\title{
User experience and satisfaction with specialty consultations and surgical care in secondary and tertiary level hospitals in Mexico
}

\author{
Svetlana V. Doubova ${ }^{1 *}$ (D), Claudia Infante-Castañeda², Sanam Roder-DeWan ${ }^{3,4}$ and Ricardo Pérez-Cuevas 5,6
}

\begin{abstract}
Background: To evaluate the association between user experience and satisfaction with specialty consultations and surgical care at the Mexican Institute of Social Security (IMSS) secondary and tertiary level hospitals.

Methods: We conducted secondary data analysis of the cross-sectional 2017 IMSS National Satisfaction Survey. The dependent variables were user satisfaction with outpatient consultation and with surgery. The study's independent variables were user experience with these services. The Lancet Global Health Commission on High Quality Health Systems in the Sustainable Development Era framework was used to guide the analysis. For each dependent variable a double-weighted Poisson regression model with robust variance was performed and considered clustering of the observations within 111 secondary level and 25 tertiary level hospitals.

Results: The study included 6713 outpatient consultation users and 528 surgery users. 83\% of users attending outpatient consultations and $86.6 \%$ of users who underwent inpatient surgery at IMSS hospitals were satisfied with the service received. The common patient negative experiences with specialty consultations and surgical care were long waiting time (40\%) and lack of hospital cleanliness (20\%). An additional concern was the lack of clinical examination during the consultation (25\%). Shorter waiting times, health provider courtesy, good communication, clinical examination, and hospital cleanliness were associated with patient satisfaction with specialty consultations. Having the surgery without prior postponement(s) and without complications increased the probability of patient satisfaction.
\end{abstract}

Conclusion: Patient satisfaction with hospital outpatient consultations and surgical care may be raised by focusing on improvement strategies to enhance positive patient experiences with care.

Keywords: User experience, User satisfaction, Outpatient consultations, Surgical care, México

\section{Background}

In the last decades, health service user experience and satisfaction surveys have been extensively used worldwide. These surveys provide valuable information on health service quality to inform decision-makers, healthcare providers and the public to guide quality improvement initiatives [1]. Repeated surveys serve to evaluate

\footnotetext{
* Correspondence: svetlana.doubova@gmail.com

${ }^{1}$ Epidemiology and Health Services Research Unit CMN Siglo XXI, Mexican Institute of Social Security, Av. Cuauhtemoc 330, Zip Code: 06720 Mexico City, Mexico

Full list of author information is available at the end of the article
}

the effectiveness of new healthcare policies and programs and improve accountability through open access to the survey results, internal feedback and benchmarking with similar healthcare providers [1].

The value of user satisfaction surveys has been proven by previous research that shows a link between better clinical (e.g., technical aspects of the process of care) and non-clinical quality of care (e.g., interpersonal care, quality of basic amenities, etc.) and higher patient satisfaction [2-6].

Patient satisfaction with healthcare is a complex construct that reflects a subjective evaluation of health

(c) The Author(s). 2019 Open Access This article is distributed under the terms of the Creative Commons Attribution 4.0 International License (http://creativecommons.org/licenses/by/4.0/), which permits unrestricted use, distribution, and 
services and providers based on personal preferences and expectations and actual experiences with care [7-9]. These experiences include technical and interpersonal aspects of healthcare, accessibility, affordability, acceptability, quality of the infrastructure and equipment at health facilities, and health outcomes. Also, patients' experiences and satisfaction with healthcare should consider person-related characteristics as potential determinants and confounders simultaneously [6], given that multiple studies found that male sex, older age, lower levels of schooling and better self-perceived health status were associated with higher patient satisfaction [9-13].

International research has reported important differences in satisfaction and experiences with healthcare in low and high-income countries. The 2005-2012 Gallup World Polls revealed that in Sub-Saharan Africa only $42 \%$ of respondents were satisfied with the availability of high-quality care, compared to $86 \%$ in Northern Europe [14]. There are multiple common and specific patient experiences among countries and healthcare providers at different levels (e.g., individual, community, institutional, primary or secondary levels) that determine satisfaction. The general population survey of the World Health Organization in 41 countries identified prompt attention, improved health outcomes, dignity and effective patient-provider communication as the most important characteristics of healthcare [15].

Hospital care comprises specialized outpatient and inpatient healthcare for people whose medical conditions cannot be resolved at the primary care level. Patient satisfaction with hospital care varies among providers within and among countries. For instance, in the United States [16], the Hospital Consumer Assessment of Healthcare Providers and Systems survey found high levels of satisfaction with care; $63 \%$ of patients rated their care as high (9 or 10 points out of 10 ), $26 \%$ as 7 or 8 , whereas only $11 \%$ gave a rating of 6 or less. However, this survey found that private or public not-for-profit hospitals were rated higher than forprofit hospitals (64.8 and $65.4 \%$ vs. $59.1 \%$ respectively). Also, hospitals within a top quartile of nursesto-patient-days ratio were rated higher than those in the bottom quartile $(70.2 \%$ vs.63.5\%). At the same time, in Peru, patient satisfaction ranged from 25 to 62.1\% among different hospitals [17-19].

During the last five years in Mexico, patient satisfaction surveys have been routinely used. Yet, the relationship between patient experiences and satisfaction with hospital care is poorly understood. Our literature review revealed only data from the Mexican Survey of Health and Nutrition [20,21] and a 2004 study from 15 hospitals in the state of Hidalgo [22]. Both sources reported $80 \%$ or higher satisfaction of patients with hospital care.
These studies identified that the primary experiences related to dissatisfaction were lack of disease-related information, unfriendly physician attitude, lack of restrooms in the waiting area and appearance of clinical complications.

The Mexican Institute of Social Security (IMSS) is the largest healthcare provider in Mexico. In 2016, IMSS had 1506 primary care clinics, 247 secondary level, and 36 tertiary level hospitals and it provided care for 63 , 480,327 affiliates (50\% of the Mexican population) [23]. On an average day, IMSS delivers 78,000 specialty consultations and 4000 surgeries. Since 2009, the IMSS National Satisfaction Survey has been carried out on a regular basis; however, its data have not been analyzed in-depth to identify the determinants of patient satisfaction and guide the design of quality improvement strategies. Therefore, the objective of this study was to evaluate the association between user experience and satisfaction with specialty consultations and surgical care at IMSS secondary and tertiary level hospitals. We hypothesized that specific positive user experiences are associated with their satisfaction with care.

\section{Methods}

This study is a secondary data analysis of the crosssectional November 2017 IMSS National Satisfaction Survey (ENSAT).

The 2017 ENSAT was conducted with users attending to medical care at facilities of any of the three levels of care (primary, secondary and tertiary), and its design used a two-stage stratified probabilistic sampling for each level of care. Our study analyzed the information for the outpatient specialty consultations and inpatient surgeries at IMSS secondary and tertiary care hospitals. In the first stage, the ENSAT sampling frame included a complete list of IMSS hospitals. The hospitals were stratified by district (IMSS is divided into 35 districts in 32 States) and level of care. Subsequently, within each district, the hospitals were selected based on probability proportional to their average number of daily specialty consultations and inpatient surgeries. In the second stage, the sampling frame for patients in each hospital was based on the list of patients who had specialty consultation or were discharged from the surgery ward. Patient selection was through systematic sampling with a random starting point and a fixed periodic interval. In each hospital, this interval was contingent on the average number of consultations or surgeries per day.

The sample size considered the absolute allowable error in the estimation of $1.1 \%$ in secondary care hospitals and $1.5 \%$ in tertiary care hospitals. The design effect ranged between 1.1 and 2.7 in secondary care hospitals and between 1.1 and 1.4 in tertiary care hospitals. The expansion factors were calculated as the inverse of the 
selection probability of each sampling unit to represent the population of IMSS daily users.

A private firm (Berumen and Associates) conducted the survey. Trained interviewers carried out direct, structured interviews with IMSS health services users $\geq 18$ years of age. The interviewers used a satisfaction questionnaire that the Center for Evaluation Research and Surveys of the National Institute of Public Health had previously validated: this included content validation by the expert group. According to this validation, the questionnaire has good content validity; yet, the results were not published in academic or other publicly available sources.

The response rate in the survey was $85 \%$ for secondary care hospitals, and $83 \%$ for tertiary care hospitals. At the secondary level of care, the final sample of the survey included 111 hospitals and 4625 users of outpatient consultation with specialists and 380 users who underwent inpatient surgery. At the tertiary level of care, the sample included 25 hospitals and 2458 users of specialty consultations and 196 users of inpatient surgery.

\section{Study variables}

The dependent variable was user satisfaction with healthcare. This variable was measured through a single question with seven response options: very satisfied, satisfied, neither satisfied nor dissatisfied, dissatisfied, very dissatisfied, not sure, decline to answer. These options were then grouped into two categories: satisfied (very satisfied, satisfied) and not satisfied (dissatisfied, very dissatisfied and neither satisfied nor dissatisfied). The last category was included in the "not satisfied" group as from our perspective those who answered that they were "neither satisfied nor dissatisfied" (4.7\% of outpatient consultation and $3.8 \%$ of surgical services users) were unable to classify as satisfactory their experience with the health services. In addition, we did not include in the analysis those users who were "not sure" or declined to answer (0.1\%: 7 users of outpatient consultation and one surgery user).

The study's independent variables were user experiences with outpatient consultation and user experience with surgical care, measured on a dichotomous scale (yes and no). We organized the existing survey variables on user experiences into five groups according to the 2018 Lancet Global Health Commission on HighQuality Health Systems conceptual framework [24], as follows (Table 1).

The analysis included the following patient sociodemographic and clinical covariates: sex (female, male); age groups ( $\leq 35$ years; $>35 \& \leq 44$ years; $>44 \& \leq 64$ years; $\geq 65$ years); schooling (incomplete elementary school or without formal education; complete elementary school or incomplete secondary school; complete secondary school or higher); region of residence (divided in seven strata from stratum 1 (lowest socioeconomic level) to 7 (highest socioeconomic level) [25]; the level of care in which service was received (secondary, or tertiary).

For patients that attended the outpatient consultation, we also analyzed the type of specialty consultation: medical-surgical, or clinical specialties, and causes of specialty consultation that were grouped according to the International Classification of Diseases 10th revision (ICD-10) code and its frequencies, with low frequency codes grouped in the "others diseases" category: (1) Neoplasms; 2) Endocrine, nutritional and metabolic diseases; 3) Mental, behavioural disorders and diseases of the nervous system; 4) Diseases of the eye and adnexa; 5) Diseases of the respiratory system and diseases of the ear; 6) Diseases of the circulatory system; 7) Diseases of the digestive system; 8) Diseases of the musculoskeletal system

Table 1 User experience with specialty consultations and surgical care organized under the Lancet Global Health Commission on High-Quality Health Systems conceptual framework

\begin{tabular}{|c|c|c|}
\hline Domains & Specialty consultation & Surgery \\
\hline I. Client focus & Waiting time for outpatient consultation in hospital outpatient area $\leq 30 \mathrm{~min}$ & $\begin{array}{l}\text { Waiting time between referral to surgery and } \\
\text { actual surgery is } \leq 20 \text { completed waiting days } \\
\text { History of surgery postponement(s) }\end{array}$ \\
\hline II. Respect & $\begin{array}{l}\text { Courtesy: Specialist greeted the patient at the beginning of the consultation } \\
\text { Clear communication: } \\
\text { Specialist gave the patient an opportunity to talk about health-related concerns } \\
\text { Specialist listened to the patient with attention and without interruptions } \\
\text { Specialist clearly answered patient questions } \\
\text { Specialist resolved patient doubts about health-related self-care }\end{array}$ & $\begin{array}{l}\text { Courtesy: Surgeon greeted patient before surgery } \\
\text { Clear communication: } \\
\text { Surgeon explained the risks and benefits of } \\
\text { surgery } \\
\text { Surgeon gave clear information to the patient's } \\
\text { relatives }\end{array}$ \\
\hline $\begin{array}{l}\text { III. Competent } \\
\text { care }\end{array}$ & Specialist performed clinical examination & \\
\hline $\begin{array}{l}\text { IV. Quality of } \\
\text { basic amenities }\end{array}$ & Hospital cleanliness was very good or good & Hospital cleanliness was very good or good \\
\hline $\begin{array}{l}\text { V. Quality } \\
\text { impact }\end{array}$ & $\begin{array}{l}\text { Quality impact on financial risk protection: Patient received all prescribed } \\
\text { medicines in the hospital pharmacy free due to their coverage by IMSS health } \\
\text { insurance (reference group did not have any prescription to fulfill) }\end{array}$ & $\begin{array}{l}\text { Quality impact on health: Patient did not have } \\
\text { complications that required another surgery }\end{array}$ \\
\hline
\end{tabular}


and connective tissue; 9) Diseases of the genitourinary system; 10) Pregnancy, childbirth and the puerperium; 11) Injury, poisoning and other consequences of external causes; 12) Others diseases; 13) Factors influencing health status and contact with health services; 14) Symptoms, signs and abnormal clinical and laboratory findings, not elsewhere classified).

For patients with surgery, we included causes of surgery variable: 1) Diseases of the digestive system; 2) Diseases of the genitourinary system; 3) Diseases of the musculoskeletal system and connective tissue; 4) Diseases of the eye and adnexa; 5) Injury, poisoning and other consequences of external causes; 6) Other types of diseases and cesarean section; 7) Symptoms, signs and abnormal clinical and laboratory findings, not elsewhere classified.

We included in our analysis causes of specialty consultation and of surgery as approximation to the patient health status because previous research has shown that patient health status is an important potential determinant of satisfaction [6].

\section{Statistical analysis}

We used descriptive statistics to analyze patient characteristics and experiences with healthcare. We performed a bivariable analysis, including chi-square tests between the dependent variable (user satisfaction) and each independent variable (user experiences), or categorical covariates.

For each model (satisfaction with outpatient consultation or with surgical care) we performed a doubleweighted Poisson regression model with robust variance. We used Poisson regression with robust variance as recommended for cross-sectional studies with highprevalence binary outcomes [26]. We applied a doubleweighted strategy with the use of survey weights and stabilized inverse probability (IP) weights to adjust the analysis for sample weights and to correct for potential missing data bias [27]. The number of participants with one or more missing values in the study variables was $370(5.2 \%, N=7083)$ for specialty consultation and 48 $(8.3 \%, N=576)$ for surgery. The IP-weights technique consists of assigning a weight to each person with complete information so that, in the analysis, they are accounting for themselves as well as for those with similar characteristics who had missing information. It allows for conditional exchangeability (within the level of measured covariates) of those without and with missing data. The denominator for IP-weights was the probability of having missing data conditional on the following covariates: sex, age, stratum of the region of residence, level of care and ICD code for the cause of specialty consultation (or cause of surgery). The numerator was the probability of "having missing data" regardless of the covariates. The multiple Poisson regression model included the dependent variable, all conceptually relevant independent variables, and covariates found in prior research related to user satisfaction and available in the ENSAT databases. Previous to the multiple regression model, we calculated crude prevalence ratio (PR) and 95\% confidence interval (CI) for each independent variable and each covariate.

Furthermore, given that ENSAT 2017 included 111 secondary level and 25 tertiary level hospitals, we put together data of the secondary and tertiary level hospitals; we included in the analysis the variable that specifies level of care and we used the "vce (cluster hospital)" command for the robust variance to explicitly state that observations were grouped within the hospitals. This decision was supported by the fact that differences in infrastructure and staff at IMSS are primarily defined by the level of care (general hospitals provide a secondary level of care and highly specialized hospitals provide a tertiary level of care).

In addition, we performed sensitivity analyses. We conducted multilevel double-weighted Poisson regressions, using random effects for hospitals, to account for the complex structure of the data with patients nested within facilities with ENSAT 2017 and 2016 data. All analyses were performed using STATA 14 software and considering estimates with $p<0.05$ to be statistically significant.

\section{Results}

Table 2 describes the socio-demographic, clinical characteristics and healthcare experiences of users attending outpatient consultations with specialists at IMSS hospitals. Out of the 6713 users, most were women (69.6\%); $23.7 \%$ of the respondents were younger than 36 years of age, $54.7 \%$ were between 36 and 64 years and $21.6 \%$ were older; with completed secondary school or higher education (65.1\%); and residents of the region of stratum four and six that correspond to medium and high socioeconomic levels. The majority (83.3\%) attended their consultation with a specialist at a secondary level hospital; $56.4 \%$ had a medical-surgical consultation, mostly due to diseases of the genitourinary system (11.6\%), injury, poisoning and other consequences of external causes $(11 \%)$, followed by neoplasms $(8.3 \%)$ and diseases of the musculoskeletal system and connective tissue (8.2\%).

Regarding the experience of patients attending outpatient consultations with a specialist: $59.2 \%$ of respondents waited for a consultation for $30 \mathrm{~min}$ or less; $81.6 \%$ reported that the specialist greeted them at the beginning of the consultation; $87.9 \%$ had the opportunity to talk about their health-related concerns; $89.4 \%$ mentioned that the specialist listened to them with attention 
Table 2 Socio-demographic, clinical characteristics and healthcare experiences of users attending outpatient consultations with specialists

\begin{tabular}{|c|c|}
\hline Variables & $\begin{array}{l}\text { Total } n=6713 \\
\text { Weighted \% }\end{array}$ \\
\hline \multicolumn{2}{|l|}{ Socio-demographic and clinical characteristics } \\
\hline Women & 69.6 \\
\hline \multicolumn{2}{|l|}{ Age groups } \\
\hline$\leq 35$ years & 23.7 \\
\hline$>35 \& \leq 44$ years & 16.7 \\
\hline$>44 \& \leq 64$ years & 38.0 \\
\hline$\geq 65$ years & 21.6 \\
\hline \multicolumn{2}{|l|}{ Schooling } \\
\hline Incomplete elementary school or without formal education & 12.5 \\
\hline Compete elementary school & 22.4 \\
\hline Complete secondary school or higher & 65.1 \\
\hline \multicolumn{2}{|l|}{ Region of residence according to the socio-economic level } \\
\hline Stratum 1 (lowest socio-economic level) & 3.8 \\
\hline Stratum 2 & 12.2 \\
\hline Stratum 3 & 10.6 \\
\hline Stratum 4 & 21.1 \\
\hline Stratum 5 & 13.3 \\
\hline Stratum 6 & 21.4 \\
\hline Stratum 7 (highest socio-economic level) & 17.6 \\
\hline \multicolumn{2}{|l|}{ Level of healthcare in which service was received } \\
\hline Secondary & 83.3 \\
\hline Tertiary & 16.7 \\
\hline \multicolumn{2}{|l|}{ Type of specialty consultation } \\
\hline Medical-surgical consultation & 56.4 \\
\hline Clinical specialties consultation & 43.6 \\
\hline \multicolumn{2}{|l|}{ Cause of specialty consultation } \\
\hline Diseases of the genitourinary system & 11.6 \\
\hline Injury, poisoning and other consequences of external causes & 11.0 \\
\hline Neoplasms & 8.3 \\
\hline Diseases of the musculoskeletal system and connective tissue & 8.2 \\
\hline Diseases of the circulatory system & 7.7 \\
\hline Endocrine, nutritional and metabolic diseases & 7.1 \\
\hline Diseases of the eye and adnexa & 6.4 \\
\hline Diseases of the respiratory system and diseases of the ear & 5.3 \\
\hline Pregnancy, childbirth and the puerperium & 5.5 \\
\hline Mental, behavioural disorders and diseases of the nervous system & 4.6 \\
\hline Diseases of the digestive system & 3.8 \\
\hline Other diseases & 5.4 \\
\hline Factors influencing health status and contact with health services & 7.2 \\
\hline Symptoms, signs and abnormal clinical and laboratory findings, not elsewhere classified & 7.9 \\
\hline \multicolumn{2}{|l|}{ Users experience with outpatient consultation } \\
\hline \multicolumn{2}{|l|}{ I. Client focus } \\
\hline Waiting time $\leq 30 \mathrm{~min}$ & 59.2 \\
\hline
\end{tabular}


Table 2 Socio-demographic, clinical characteristics and healthcare experiences of users attending outpatient consultations with specialists (Continued)

\begin{tabular}{|c|c|}
\hline Variables & $\begin{array}{l}\text { Total } n=6713 \\
\text { Weighted \% }\end{array}$ \\
\hline \multicolumn{2}{|l|}{ II. Respect } \\
\hline Specialist greeted patient at the beginning of the consultation & 81.6 \\
\hline Specialist gave the patient an opportunity to talk about health-related concerns & 87.9 \\
\hline Specialist listened to the patient with attention and without interruptions & 89.4 \\
\hline Specialist answered clearly patient's questions & 90.7 \\
\hline Specialist resolved patient's doubts about health-related self-care & 80.9 \\
\hline \multicolumn{2}{|l|}{ III. Competent care } \\
\hline Specialist performed clinical examination & 75.0 \\
\hline \multicolumn{2}{|l|}{ IV. Quality of basic amenities } \\
\hline \multicolumn{2}{|l|}{ Hospital's cleanliness } \\
\hline Good, very good & 78.3 \\
\hline Regular, bad or terrible & 21.7 \\
\hline \multicolumn{2}{|l|}{ V. Quality impact on financial risk protection } \\
\hline \multicolumn{2}{|l|}{ Patients received all prescribed medicines in the hospital pharmacy } \\
\hline Yes & 47.2 \\
\hline No & 2.8 \\
\hline Did not have any prescription to fill & 50.0 \\
\hline \multicolumn{2}{|l|}{ Overall satisfaction } \\
\hline Satisfied with consultation & 83.0 \\
\hline
\end{tabular}

and without interruptions; $90.7 \%$ considered that the specialist answered their questions clearly; $80.9 \%$ responded that the specialist resolved their doubts about health-related self-care; $75 \%$ reported that the specialist performed a clinical examination. In addition, 50\% did not receive any prescription, $47.2 \%$ with prescription received all medicines at the hospital pharmacy; and $2.8 \%$ did not receive prescribed medicines, since the pharmacy was out of stock. Most patients reported that the cleanliness of the hospital was good $(78.3 \%) ; 83.0 \%$ of users attending outpatient consultations at IMSS hospitals were satisfied with the service received.

Table 3 depicts the socio-demographic, clinical characteristics and healthcare experiences of users who had inpatient surgery. Out of the 528 users, most were women (60.3\%); $29.3 \%$ of the respondents were younger than 36 years of age, $53.2 \%$ were between 36 and 64 years and $17.5 \%$ were older; with completed secondary school or higher education (71.9\%); and were residents of the region of stratum four and six, corresponding to medium and high socio-economic levels. Additionally, 82.6\% underwent surgery at secondary level hospitals, and the most frequent surgery indications were diseases of the digestive $(24.6 \%)$ and genitourinary $(13.7 \%)$ systems.

Overall, $71.1 \%$ of users waited for $\leq 20$ days between being referred to surgery and undergoing the actual surgery; $11.1 \%$ experienced one or more surgery postponements; $82.2 \%$ informed that the surgeon greeted them before the operation; $87.2 \%$ reported that the surgeon explained the risk and benefits of the surgery; $85.8 \%$ responded that the surgeon gave clear information to their relatives; $13 \%$ of the patients had surgical complications that required another surgery; $76.4 \%$ reported that the cleanliness of the hospital was good; $86.6 \%$ of users who underwent inpatient surgery at IMSS hospitals were satisfied with the service received.

Table 4 presents the results of the bivariate analysis and multiple double-weighted Poisson regression analysis to identify user experience related to satisfaction with outpatient consultation. The results of the bivariate analysis show that patients with shorter waiting time, those who were greeted by the specialist, who had an opportunity to talk about health-related concerns, who were listened to without interruption, who received clear answers to their questions, who resolved doubts about their self-care, who had a clinical examination, and who were attended to in a clean hospital were more likely to be satisfied with outpatient consultation in comparison with those who did not $(p<0.05)$. Also, older patients living in the areas of the lowest or highest socioeconomic level (region of stratum 1 and 7) and those who received care at the tertiary level hospital more often reported being satisfied with outpatient consultation $(\mathrm{p}<0.05)$. 
Table 3 Socio-demographic, clinical characteristics and healthcare experiences of users with surgical care

\begin{tabular}{|c|c|}
\hline \multirow[t]{2}{*}{ Variables } & \multirow{2}{*}{$\begin{array}{l}\text { Total } n=528 \\
\text { Weighted \% }\end{array}$} \\
\hline & \\
\hline \multicolumn{2}{|l|}{ Socio-demographic and clinical characteristics } \\
\hline Women & 60.3 \\
\hline \multicolumn{2}{|l|}{ Age groups } \\
\hline$\leq 35$ years & 29.3 \\
\hline$>35 \& \leq 44$ years & 20.6 \\
\hline$>44 \& \leq 64$ years & 32.6 \\
\hline$\geq 65$ years & 17.5 \\
\hline \multicolumn{2}{|l|}{ Schooling } \\
\hline Incomplete elementary school or without formal education & 11.5 \\
\hline Compete elementary school & 16.6 \\
\hline Complete secondary school or higher & 71.9 \\
\hline \multicolumn{2}{|l|}{ Region of residence according to the socio-economic level } \\
\hline Stratum 1 (lowest socio-economic level) & 1.6 \\
\hline Stratum 2 & 12.6 \\
\hline Stratum 3 & 5.1 \\
\hline Stratum 4 & 24.1 \\
\hline Stratum 5 & 15.6 \\
\hline Stratum 6 & 20.7 \\
\hline Stratum 7 (highest socio-economic level) & 20.3 \\
\hline \multicolumn{2}{|l|}{ Level of healthcare in which surgery was performed } \\
\hline Secondary & 82.6 \\
\hline Tertiary & 17.4 \\
\hline \multicolumn{2}{|l|}{ Cause of surgery } \\
\hline Diseases of the digestive system & 24.6 \\
\hline Diseases of the genitourinary system & 13.7 \\
\hline Diseases of the musculoskeletal system and connective tissue & 12.8 \\
\hline Injury, poisoning and other consequences of external causes & 8.9 \\
\hline Diseases of the eye and adnexa & 8.2 \\
\hline Other types of diseases and cesarean section & 17.4 \\
\hline Symptoms, signs and abnormal clinical and laboratory findings, not elsewhere classified & 14.4 \\
\hline \multicolumn{2}{|l|}{ Users experience with surgery } \\
\hline \multicolumn{2}{|l|}{ I. Client focus } \\
\hline Wait time between recommendation for surgery and actual surgery $\leq 20$ days & 71.1 \\
\hline History of surgery postponement(s) & 11.1 \\
\hline \multicolumn{2}{|l|}{ II. Respect } \\
\hline Surgeon greeted patient before a surgery & 82.2 \\
\hline Surgeon explained the risks and benefits of a surgery & 87.2 \\
\hline Surgeon gave clear information to the patient's relatives & 85.8 \\
\hline \multicolumn{2}{|l|}{ III. Quality of basic amenities } \\
\hline Hospital's cleanliness very good or good & 76.4 \\
\hline \multicolumn{2}{|l|}{ IV. Quality impact on health } \\
\hline Patient had complications that required another surgery & 13.0 \\
\hline \multicolumn{2}{|l|}{ Overall satisfaction } \\
\hline Satisfied with surgery & 86.6 \\
\hline
\end{tabular}


To build the multiple Poisson regression model we used all conceptually relevant variables. The coefficients represent prevalence ratios (PR); their interpretation is the same as for risk ratios. The analysis revealed that the following patient experiences increase the probability of satisfaction: shorter waiting time (adjusted PR:1.11; 95\%CI: 1.07-1.14), an opportunity to talk about health-related concerns (adjusted PR:1.11; 95\%CI:1.03-1.19), being listened to without interruption (adjusted PR:1.16; 95\%CI: $1.05-1.29$ ), receiving clear answers to their questions (adjusted PR:1.17; 95\%CI:1.04-1.31), perceiving that their doubts about self-care were resolved (adjusted PR:1.16; 95\%CI:1.11-1.22), being examined (adjusted PR:1.06; 95\%CI:1.02-1.11) and experiencing hospital cleanliness (adjusted PR:1.19; 95\%CI:1.14-1.26). Additionally, several patient socio-demographic and clinical characteristics increased the probability of patient satisfaction, including being a resident of stratum 1 (lowest socioeconomic level) and 4 (medium socioeconomic level) (adjusted PR:1.09; 95\%CI:1.01-1.17 and PR:1.06; 95\%CI:1.01-1.12, respectively) and having a consultation due to a disease of the genitourinary system (adjusted PR:1.07; 95\%CI:1.01-1.14).

Table 5 presents the results of the bivariate analysis and multiple double-weighted Poisson regression analysis to identify user experiences related to satisfaction with surgery. In the bivariate analysis, patients with incomplete elementary school or without formal education, those without prior postponement(s) of the surgery, those who were greeted by the surgeon before the surgery, those whose relatives received clear information about the surgery, and those who did not have complications and received care at a clean hospital were more likely to report being satisfied with the surgery in comparison with those who did not $(p<0.05)$.

The multiple Poisson regression analysis revealed that having the surgery without prior postponement(s) (adjusted PR:1.24; 95\%CI:1.002-1.54) and without complications (adjusted PR:1.30; 95\%CI:1.03-1.64) increased the probability of patient satisfaction with surgery. Also, being a resident of stratum 1 (lowest level of welfare) and 4 (medium level of welfare) (adjusted PR:1.23; 95\%CI:1.01-1.51 and PR:1.19; 95\%CI:1.03-1.38, respectively) and having surgery due to a digestive system disease (adjusted PR:1.19; 95\%CI:1.005-1.41) were additional factors that increased the probability of patient satisfaction with surgery.

The results of the sensitivity analyses using multilevel regressions with ENSAT 2017 and 2016 data revealed similar associations between the same independent and dependent variables in terms of direction and statistical significance (Additional file 1). In addition, in 2016, satisfaction with surgery increased when the surgeons explained the risks and benefits of surgery to the patients and gave clear information to their relatives.
Discussion The present study found that lengthy waiting time and lack of hospital cleanliness constituted common patient negative experiences with specialty consultations and surgical care. An additional concern was the lack of clinical examination during the consultations. Notably, shorter waiting times, health provider courtesy, good communication, clinical examination, and hospital cleanliness were associated with patient satisfaction with specialty consultations; while having the surgery without prior postponement(s) and without complications increased the probability of patient satisfaction with surgical care. To the best of our knowledge, this finding is novel for Mexico and Latin America, as the association of patient experiences with hospital care and their satisfaction was not previously investigated in these countries.

Positive patient experiences with healthcare and satisfaction are important indicators of healthcare quality. The present study found that user experience is a major predictor of satisfaction in the multiple regression model that included patient socio-demographic and clinical factors. Evaluating user experience is important because positive experiences are associated with better health outcomes, and negative experiences can guide healthcare improvement initiatives [28]. A systematic review of 55 studies found consistent positive associations between patient experience and adherence to recommended clinical practice, medication and preventive activities (e.g., use of screening services and immunization), among others [28].

The high levels of satisfaction with outpatient consultations and inpatient surgical care $(>80 \%)$ observed in our study has been a frequent finding in Mexico and other low and middle-income countries [20-22, 24]. Such a finding should be interpreted with caution because rather than signaling high quality of care, this result can be influenced by low expectations and low health literacy of people unaware of the quality of healthcare that the health system should provide them with. Also, the "social desirability" factor might influence positive opinions. Therefore, to obtain more constructive insights about patients' expectations and satisfaction, health providers should build up the health literacy of the population they serve [29].

In both consultation with specialist and surgery, the higher percentage of positive patient experiences were observed in the "respect" domain of the framework of the Lancet Global Health Commission on High-Quality Health Systems. This domain included health provider courtesy and clear communication and was reflected in the fact that over $80 \%$ of patients reported that the specialists greeted them, let them talk about their healthrelated concerns, listened without interruption, gave clear answers to their questions and resolved their 
Table 4 User experience related to satisfaction with outpatient consultation ( $n=6713)$

\begin{tabular}{|c|c|c|c|c|}
\hline \multirow{2}{*}{$\begin{array}{l}\text { TYPE OF ANALYSIS } \\
\text { VARIABLES }\end{array}$} & \multicolumn{2}{|c|}{ Bivariable analysis } & \multirow{2}{*}{$\begin{array}{l}\text { Simple double-weighted } \\
\text { Poisson regression analysis } \\
\text { Crude PR } \\
(95 \% \mathrm{Cl})\end{array}$} & \multirow{2}{*}{$\begin{array}{l}\text { Multiple double-weighted } \\
\text { Poisson regression analysis } \\
\text { Adjusted PR } \\
(95 \% \mathrm{Cl})\end{array}$} \\
\hline & $\begin{array}{l}\text { Satisfied } \\
n=5738\end{array}$ & $\begin{array}{l}\text { Dissatisfied } \\
n=975\end{array}$ & & \\
\hline & $\begin{array}{l}\text { Weighted } \\
\%\end{array}$ & $\begin{array}{l}\text { Weighted } \\
\%\end{array}$ & & \\
\hline
\end{tabular}

Users experience with outpatient consultation

I. Client focus

Wait time*

$\leq 30 \mathrm{~min}$

$>30 \mathrm{~min}$

87.8

76.1

12.2

23.9

II. Respect

Specialist greeted patient at the beginning of the consultation*

$\begin{array}{lll}\text { Yes } & 85.8 & 14.2 \\ \text { No } & 70.7 & 29.3\end{array}$

Specialist gave the patient an opportunity to talk about health-related concerns*

$\begin{array}{lll}\text { Yes } & 85.1 & 14.9\end{array}$

No

$67.8 \quad 32.2$

Specialist listened to the patient with attention and without interruptions*

Yes

$85.8 \quad 14.3$

No

59.7

40.3

Specialist answered clearly patients' questions*

$\begin{array}{ll}\text { Yes } & 85.5 \\ \text { No } & 58.6\end{array}$

Specialist resolved patients' doubts about the health-related self-care*

Yes

No

III. Competent care

Specialist performed clinical examination*

Yes

No

IV. Quality of basic amenities

Hospital's cleanliness*

Good, very good

Regular, bad or terrible

V. Quality impact on financial risk protection

Patients received all prescribed medicines in the hospital pharmacy*

$\begin{array}{lll}\text { Yes } & 83.5 & 16.4 \\ \text { No } & 71.8 & 28.2 \\ \text { Did not have any prescription to fulfill } & 83.2 & 16.8\end{array}$

Covariates

Patients' socio-demographic and clinical characteristics

Men

Women

83.6

82.8

82.9

17.1

Age groups*

$$
\leq 35 \text { years }
$$

$1.15(1.11 ; 1.90)$

Ref.

1.21 (1.15; 1.28)

Ref

1.25 (1.17; 1.34)

Ref.

1.44 (1.32; 1.56)

Ref.

1.46 (1.34; 1.59)

Ref.

1.27 (1.20; 1.34)

Ref.

1.13 (1.09; 1.18)

Ref.

$1.06(1.02 ; 1.11)$

Ref.

$1.19(1.14 ; 1.26)$

$1.28(1.21 ; 1.34)$

Ref.

Ref.

1.16 (1.03; 1.31)

Ref.

1.16 (1.03; 1.30)

$1.09(0.97 ; 1.21)$

Ref.

$1.11(0.99 ; 1.23)$

$.04(0.99 ; 1.09)$

Ref.

1.11 (1.03; 1.19)

Ref.

1.16 (1.05; 1.29)

Ref.

$1.17(1.04 ; 1.31)$

Ref.

$1.16(1.11 ; 1.22)$

Ref.
11 (1.07; 1.14)

Ref.

Ref.

Ref.

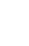


Table 4 User experience related to satisfaction with outpatient consultation ( $n=6713)$ (Continued)

\begin{tabular}{|c|c|c|c|c|}
\hline \multirow{3}{*}{$\begin{array}{l}\text { TYPE OF ANALYSIS } \\
\text { VARIABLES }\end{array}$} & \multicolumn{2}{|c|}{ Bivariable analysis } & \multirow{3}{*}{$\begin{array}{l}\text { Simple double-weighted } \\
\text { Poisson regression analysis } \\
\text { Crude PR } \\
(95 \% \mathrm{Cl})\end{array}$} & \multirow{3}{*}{$\begin{array}{l}\text { Multiple double-weighted } \\
\text { Poisson regression analysis } \\
\text { Adjusted PR } \\
(95 \% \mathrm{Cl})\end{array}$} \\
\hline & \multirow{2}{*}{$\begin{array}{l}\text { Satisfied } \\
n=5738 \\
\text { Weighted } \\
\%\end{array}$} & \multirow{2}{*}{$\begin{array}{l}\text { Dissatisfied } \\
n=975 \\
\text { Weighted } \\
\%\end{array}$} & & \\
\hline & & & & \\
\hline$>35 \& \leq 44$ years & 81.3 & 18.7 & $0.98(0.93,1.03)$ & $1.00(0.97 ; 1.04)$ \\
\hline$>44 \& \leq 64$ years & 82,1 & 17.9 & $0.99(0.95,1.03)$ & $1.01(0.97 ; 1.05)$ \\
\hline$\geq 65$ years & 86.2 & 13.8 & $1.04(0.99,1.08)$ & $1.04(0.99 ; 1.09)$ \\
\hline \multicolumn{5}{|l|}{ Schooling } \\
\hline Incomplete elementary school or without formal education & 85.3 & 14.7 & $1.04(0.99 ; 1.08)$ & $1.02(0.98 ; 1.06)$ \\
\hline Compete elementary school & 84.1 & 15.9 & $1.02(0.99 ; 1.06)$ & $1.01(0.97 ; 1.05)$ \\
\hline Complete secondary school or higher & 82.2 & 17.8 & Ref. & Ref. \\
\hline \multicolumn{5}{|l|}{ Region of residence* } \\
\hline Stratum 1 & 87.2 & 12.8 & $1.07(1.01 ; 1.13)$ & $1.09(1.01 ; 1.17)$ \\
\hline Stratum 2 & 83.3 & 16.7 & $1.02(0.97 ; 1.07)$ & $1.00(0.95 ; 1.05)$ \\
\hline Stratum 3 & 82,6 & 17.4 & $1.01(0.95 ; 1.07)$ & $1.03(0.98 ; 1.08)$ \\
\hline Stratum 4 & 83.8 & 16.2 & $1.02(0.97 ; 1.08)$ & $1.06(1.01 ; 1.12)$ \\
\hline Stratum 5 & 79.1 & 20.9 & $0.97(0.91 ; 1.03)$ & $1.03(0.96 ; 1.10)$ \\
\hline Stratum 6 & 81.8 & 18.2 & Ref. & Ref. \\
\hline Stratum 7 & 85.9 & 14.1 & $1.05(0.99 ; 1.10)$ & $1.04(0.99 ; 1.08)$ \\
\hline \multicolumn{5}{|l|}{ Level of healthcare* } \\
\hline Secondary & 81.8 & 18.2 & Ref. & Ref. \\
\hline Tertiary & 89.4 & 10.6 & $1.09(1.07 ; 1.12)$ & $1.08(1.05 ; 1.11)$ \\
\hline \multicolumn{5}{|l|}{ Type of specialty consultation } \\
\hline Medical-surgical consultation & 82.1 & 17.9 & $1.03(0.99 ; 1.05)$ & $1.02(0.99 ; 1.06)$ \\
\hline Clinical specialties consultation & 84.2 & 15.8 & Ref. & Ref. \\
\hline \multicolumn{5}{|l|}{ Cause of specialty consultation } \\
\hline Neoplasms & 83.8 & 16.2 & $1.04(0.97 ; 1.13)$ & $1.05(0.98 ; 1.12)$ \\
\hline Endocrine, nutritional and metabolic diseases & 87.3 & 12.7 & $1.09(1.01 ; 1.17)$ & $1.07(0.99 ; 1.14)$ \\
\hline $\begin{array}{l}\text { Mental, behavioural disorders and diseases of the nervous } \\
\text { system }\end{array}$ & 86.3 & 13.7 & $1.08(0.99 ; 1.17)$ & $1.08(0.98 ; 1.19)$ \\
\hline Diseases of the eye and adnexa & 81.2 & 18.8 & $1.01(0.93 ; 1.10)$ & $1.00(0.93 ; 1.08)$ \\
\hline Diseases of the respiratory system and diseases of the ear & 83.9 & 16.1 & $1.05(0.98 ; 1.14)$ & $1.04(0.96 ; 1.13)$ \\
\hline Diseases of the circulatory system & 83.6 & 16.4 & $1.04(0.96 ; 1.13)$ & $1.01(0.93 ; 1.09)$ \\
\hline Diseases of the digestive system & 81.1 & 18.9 & $1.01(0.92 ; 1.11)$ & $1.00(0.91 ; 1.10)$ \\
\hline $\begin{array}{l}\text { Diseases of the musculoskeletal system and connective } \\
\text { tissue }\end{array}$ & 78.9 & 21.1 & $0.98(0.91 ; 1.07)$ & $1.01(0.93 ; 1.10)$ \\
\hline Diseases of the genitourinary system & 84.6 & 15.4 & $1.05(0.98 ; 1.13)$ & $1.07(1.004 ; 1.14)$ \\
\hline Pregnancy, childbirth and the puerperium & 85.2 & 14.8 & $1.06(0.98 ; 1.15)$ & $1.04(0.97 ; 1.11)$ \\
\hline $\begin{array}{l}\text { Injury, poisoning and other consequences of external } \\
\text { causes }\end{array}$ & 80.1 & 19.9 & $0.99(0.93 ; 1.07)$ & $1.02(0.96 ; 1.09)$ \\
\hline Other diseases & 85.5 & 14.5 & $1.06(0.98 ; 1.16)$ & $1.07(0.98 ; 1.15)$ \\
\hline $\begin{array}{l}\text { Factors influencing health status and contact with health } \\
\text { services }\end{array}$ & 83.6 & 16.4 & $1.04(0.96 ; 1.12)$ & $1.02(0.95 ; 1.10)$ \\
\hline $\begin{array}{l}\text { Symptoms, signs and abnormal clinical and laboratory } \\
\text { findings, not elsewhere classified }\end{array}$ & 80.2 & 19.8 & Ref. & Ref. \\
\hline
\end{tabular}

${ }^{*} p<0.05$ in bivariate analysis. PR: prevalence ratios; Cl: confidence interval. The bold values highlight the statistically significant adjusted PR 
doubts. Also, the experiences related to clear communication during the consultation with the specialist were associated with an increased probability of patient satisfaction. These results are consistent with studies from other countries [13, 30-32]. In addition, satisfaction with effective patient-provider communication is associated with better patient adherence to the providers' recommendations, and better functional and psychological health [33, 34]. Therefore, improving patient-provider communication is crucial and can be achieved through training health professionals in communication skills.

User experience in the "client focus domain" that included waiting time for outpatient consultation in hospital outpatient area and time elapsed between referral to the surgery and surgery realization, should improve. We observed that $40.8 \%$ of patients reported that waiting for specialist consultation was longer than $30 \mathrm{~min}$ and one out of three patients had to wait for more than 20 days to undergo surgery. Interviews with patients in 41 countries identified prompt attention as the most critical characteristic of the non-clinical quality of care [15]. The problems of lengthy waiting time for consultation or elective surgery is an essential concern in both high and low-income countries [35]. The imbalance in demand and supply is the usual explanation for long waiting times. The imbalance occurs if patient demand exceeds the supply of health care providers and hospital beds [36]. The probability of patient satisfaction is higher if they wait less than $30 \mathrm{~min}$ [37]. To address long waiting times, most member states of the Organisation for Economic Cooperation and Development monitor national waiting times and have a national waiting time care guarantee; yet to improve waiting time, healthcare systems should invest in the strengthening of their supply capacity [36].

One out of ten patients that underwent surgery reported that the surgery had been postponed before. At the same time, not having the surgery postponed was one of the factors associated with patient satisfaction. These results are consistent with those from the analysis of complaints after postponed surgeries submitted to the National Commission of Medical Arbitration in Mexico [38] and the results from other countries that revealed the negative impact of postponements on the emotional state of patients and their families [39, 40].

A quarter of the patients who attended the outpatient consultation did not have a clinical examination that forms the essential part of "competent care". This finding is consistent with those from other low and-middle income countries, as revealed by the Lancet Global Health Commission on High-Quality Health Systems. In our study, clinical examination increased the probability of patient satisfaction. Therefore, healthcare providers training should focus on "competent care" including clinical examination in each consultation.

Two out of every ten patients considered that the IMSS hospitals lack good cleanliness. According to the World Health Organization, hospital cleanliness is an essential feature of Health System Responsiveness. However, similar to our findings, several studies from other low and middle-income countries found that their health facilities lack cleanliness [35, 41]. Also, good hospital cleanliness was associated with patient satisfaction.

Surgery without complications was another factor associated with patient satisfaction. Current evidence on the association of in-hospital health outcomes with patient satisfaction varied among countries and studies. In Germany [42], a survey of 39 hospitals identified the outcome of treatment as the main determinate of patient satisfaction. A study from 15 hospitals in the State of Hidalgo, Mexico [22], reported that patient dissatisfaction was associated with the presence of complications. Also, a study of medical complaints due to surgical complications in Mexico revealed that the absence of actions or inappropriate actions at the facility level (e.g., ignoring complaints or lack of information by health provider), were associated with a higher probability of complaints to the National Commission of Medical Arbitration [43]. Several other studies from the United States found that postoperative complications had no impact on overall patient satisfaction ranking $[44,45]$.

The ENSAT uses a single question to evaluate patient satisfaction. The current evidence supports that a single question might be a useful survey tool for patient satisfaction measurement [46]. Concurrently, the complexity of the consumer satisfaction construct and the limitations of a single overall question (e.g., acquiescent response, social desirability bias, as well as the need to reduce the entire history of interaction with a service to a single rating) are widely recognized [47-51]. Consequently, multiple researchers suggest using jointly a single question and specific patient experiences measures to provide insights on patient satisfaction and quality of care improvement [4751]. Unlike to a single question of overall satisfaction that requires the consumer to consider all aspects of the service to come to a final decision, the measurement of experiences of care are more precise and reflect judgments about specific events or situations.

The results of the present study contribute to the knowledge of how the specific experiences with hospital healthcare are related to the overall satisfaction in the context of Mexican culture and support the simultaneous use of a single question and patient experiences measures.

The study has several strengths including: (1) focus on user experience that is aligned with the global trend of promoting patient-centered care; specifically, the study 
Table 5 User experience related to satisfaction with surgical care $(n=528)$

\begin{tabular}{|c|c|c|c|c|}
\hline \multirow{3}{*}{$\begin{array}{l}\text { TYPE OF ANALYSIS } \\
\text { VARIABLES }\end{array}$} & \multicolumn{2}{|c|}{ Bivariable analysis } & \multirow{3}{*}{$\begin{array}{l}\text { Simple double-weighted } \\
\text { Poisson regression analysis } \\
\text { Crude PR } \\
(95 \% \mathrm{Cl})\end{array}$} & \multirow{3}{*}{$\begin{array}{l}\text { Multiple double-weighted } \\
\text { Poisson regression analysis } \\
\text { Adjusted PR } \\
(95 \% \mathrm{Cl})\end{array}$} \\
\hline & \multirow{2}{*}{$\begin{array}{l}\text { Satisfied } \\
n=457 \\
\text { Weighted } \\
\%\end{array}$} & $\begin{array}{l}\text { Dissatisfied } \\
n=71\end{array}$ & & \\
\hline & & $\begin{array}{l}\text { Weighted } \\
\%\end{array}$ & & \\
\hline \multicolumn{5}{|l|}{ Users experience with a surgery } \\
\hline \multicolumn{5}{|l|}{ I. Client focus } \\
\hline \multicolumn{5}{|l|}{ Waiting time } \\
\hline$\leq 20$ days & 86.6 & 13.4 & $1.05(0.93 ; 1.18)$ & $1.04(0.93 ; 1.17)$ \\
\hline$\geq 21$ days & 84.1 & 15.9 & & Ref. \\
\hline \multicolumn{5}{|l|}{ Previous surgery postponement(s)* } \\
\hline Yes & 67.7 & 32.3 & Ref. & Ref. \\
\hline No & 88.1 & 11.9 & $1.26(0.99 ; 1.60)$ & $1.24(1.002 ; 1.54)$ \\
\hline \multicolumn{5}{|l|}{ II. Respect } \\
\hline \multicolumn{5}{|l|}{ Surgeon greeted patient before a surgery* } \\
\hline Yes & 88.6 & 11.4 & $0.82(0.69 ; 0.98)$ & $1.10(0.94 ; 1.30)$ \\
\hline No & 73.1 & 26.9 & Ref. & Ref. \\
\hline \multicolumn{5}{|l|}{ Surgeon explained the risks and benefits of a surgery } \\
\hline Yes & 87.2 & 12.8 & $1.10(0.95 ; 1.27)$ & $0.99(0.85 ; 1.15)$ \\
\hline No & 76.5 & 23.5 & Ref. & Ref. \\
\hline \multicolumn{5}{|l|}{ Surgeon gave clear information to the patient's relatives* } \\
\hline Yes & 89.9 & 10.1 & $1.39(1.12 ; 1.72)$ & $1.21(0.99 ; 1.49)$ \\
\hline No & 65.8 & 34.2 & Ref. & Ref. \\
\hline \multicolumn{5}{|l|}{ III. Quality of basic amenities } \\
\hline \multicolumn{5}{|l|}{ Hospital's cleanliness* } \\
\hline Very good or good, & 89.4 & 10.6 & $1.21(1.03 ; 1.41)$ & $1.13(0.98 ; 1.30)$ \\
\hline Regular, bad or terrible & 74.3 & 25.7 & Ref. & Ref. \\
\hline \multicolumn{5}{|l|}{ IV. Quality impact on health } \\
\hline \multicolumn{5}{|l|}{ Patient had complications that required another surgery* } \\
\hline Yes & 63.5 & 36.5 & Ref. & Ref. \\
\hline No & 89.2 & 10.8 & $1.38(1.08 ; 1.76)$ & $1.30(1.03 ; 1.64)$ \\
\hline \multicolumn{5}{|l|}{ Covariates } \\
\hline \multicolumn{5}{|l|}{ Patients' socio-demographic and clinical characteristics } \\
\hline Men & 85.8 & 14.2 & $1.00(0.91 ; 1.11)$ & $1.00(0.93 ; 1.09)$ \\
\hline Women & 85.9 & 14.1 & Ref. & Ref. \\
\hline \multicolumn{5}{|l|}{ Age groups } \\
\hline$\leq 35$ years & 84.3 & 15.7 & Ref. & Ref. \\
\hline$>35 \& \leq 44$ years & 81.0 & 19.0 & $0.94(0.78 ; 1.13)$ & $0.97(0.84 ; 1.13)$ \\
\hline$>44 \& \leq 64$ years & 86.8 & 13.2 & $1.05(0.94 ; 1.18)$ & $1.04(0.94 ; 1.14)$ \\
\hline$\geq 65$ years & 92.3 & 7.7 & $1.11(0.98 ; 1.25)$ & $1.08(0.93 ; 1.25)$ \\
\hline \multicolumn{5}{|l|}{ Schooling* } \\
\hline Incomplete elementary school or without formal education & 93.9 & 6.1 & $1.14(1.05 ; 1.24)$ & $1.07(0.98 ; 1.17)$ \\
\hline Compete elementary school & 89.8 & 10.2 & $1.09(0.99 ; 1.21)$ & $1.07(0.98 ; 1.17)$ \\
\hline Complete secondary school or higher & 82.0 & 18.0 & Ref. & Ref. \\
\hline
\end{tabular}

Region of residence 
Table 5 User experience related to satisfaction with surgical care $(n=528)$ (Continued)

\begin{tabular}{|c|c|c|c|c|}
\hline \multirow{3}{*}{$\begin{array}{l}\text { TYPE OF ANALYSIS } \\
\text { VARIABLES }\end{array}$} & \multicolumn{2}{|c|}{ Bivariable analysis } & \multirow{3}{*}{$\begin{array}{l}\text { Simple double-weighted } \\
\text { Poisson regression analysis } \\
\text { Crude PR } \\
(95 \% \mathrm{Cl})\end{array}$} & \multirow{3}{*}{$\begin{array}{l}\text { Multiple double-weighted } \\
\text { Poisson regression analysis } \\
\text { Adjusted PR } \\
(95 \% \mathrm{Cl})\end{array}$} \\
\hline & \multirow{2}{*}{$\begin{array}{l}\text { Satisfied } \\
n=457 \\
\text { Weighted } \\
\%\end{array}$} & $\begin{array}{l}\text { Dissatisfied } \\
n=71\end{array}$ & & \\
\hline & & $\begin{array}{l}\text { Weighted } \\
\%\end{array}$ & & \\
\hline Stratum 1 & 93.1 & 6.9 & $1.11(0.90 ; 1.37)$ & $1.23(1.01 ; 1.51)$ \\
\hline Stratum 2 & 77.9 & 22.1 & Ref. & Ref. \\
\hline Stratum 3 & 92.9 & 7.1 & $1.18(1.03 ; 1.35)$ & $1.13(0.97 ; 1.32)$ \\
\hline Stratum 4 & 91.4 & 8.6 & $1.16(1.02 ; 1.32)$ & $1.19(1.03 ; 1.38)$ \\
\hline Stratum 5 & 83.1 & 16.9 & $0.99(0.81,1.22)$ & $1.10(0.90 ; 1.35)$ \\
\hline Stratum 6 & 82.1 & 17.9 & $1.04(0.87 ; 1.24)$ & $1.06(0.90 ; 1.26)$ \\
\hline Stratum 7 & 87.8 & 12.2 & $1.08(0.91,1.27)$ & $1.12(0.96 ; 1.30)$ \\
\hline \multicolumn{5}{|l|}{ Level of healthcare } \\
\hline Secondary & 85.1 & 14.9 & Ref. & Ref. \\
\hline Tertiary & 89.7 & 10.3 & $1.01(0.90 ; 1.14)$ & $1.04(0.94 ; 1.15)$ \\
\hline \multicolumn{5}{|l|}{ Cause of surgery } \\
\hline Diseases of the digestive system & 87.8 & 12.2 & $1.15(0.92 ; 1.44)$ & $1.19(1.005 ; 1.41)$ \\
\hline Diseases of the genitourinary system & 78.2 & 21.8 & Ref. & Ref. \\
\hline $\begin{array}{l}\text { Diseases of the musculoskeletal system and connective } \\
\text { tissue }\end{array}$ & 87.4 & 12.6 & $1.18(0.94 ; 1.48)$ & $1.15(0.95 ; 1.38)$ \\
\hline Diseases of the eye and adnexa & 90.6 & 9.4 & $1.24(1.01 ; 1.52)$ & $1.17(0.95 ; 1.45)$ \\
\hline $\begin{array}{l}\text { Injury, poisoning and other consequences of external } \\
\text { causes }\end{array}$ & 75.4 & 24.6 & $1.03(0.76 ; 1.39)$ & $1.03(0.85 ; 1.24)$ \\
\hline Other types of diseases and cesarean section & 87,5 & 12.5 & $1.20(0.97 ; 1.47)$ & $1.13(0.94 ; 1.34)$ \\
\hline $\begin{array}{l}\text { Symptoms, signs and abnormal clinical and laboratory } \\
\text { findings, not elsewhere classified }\end{array}$ & 90.2 & 9.8 & $1.20(0.97 ; 1.48)$ & $1.13(0.95 ; 1.35)$ \\
\hline
\end{tabular}

${ }^{*} \mathrm{p}<0.05$ in bivariate analysis. PR: prevalence ratios; Cl: confidence interval. The bold values highlight the statistically significant adjusted PR

adds relevant information to the still limited evidence on specific patients experiences associated with satisfaction with hospital outpatient and surgical care in a middle income country. (2) Use of the 2018 Lancet Global Health Commission on High-Quality Health Systems conceptual framework to guide the study analysis. (3) The representativeness of the population-based survey at national, states and hospital levels. (4) IP weighting that can be considered a strength of this study, as IP weights provide control against possible selection bias arising from missing data. (5) Data from a single health system that comprises the information on which hospital each person went to; this is particularly useful for potential improvement efforts because relevant results can be shared with specific facilities.

At the same time our study has several limitations. First, this study was the analysis of a cross-sectional survey that does not allow for making causal inferences or identifying the direction of the association between the study variables. Second, due to the nature of the study (secondary data analysis), it was limited to the survey information; for instance, ENSAT lacks information on other important patient experiences, such as confidence and trust in healthcare provider, time spent with provider, dignity, and privacy, among others. In addition, the survey does not provide information on patient healthcare expectations and preferences that are important to understand patient satisfaction. These constructs should be included in future ENSAT surveys. Third, due to the characteristics of the sampling frame, there is a high probability of capturing surgery patients with shorter hospital stays since the sampling frame included patients who were discharged immediately after surgery. Finally, the results of our study can be generalizable only to the IMSS hospitals users, as the survey did not include users of the Ministry of Health or private hospitals.

In conclusion, patient satisfaction with outpatient consultations and surgical care may be increased through focusing on improvement strategies aimed at enhancing positive experiences associated with good satisfaction. These include shorter waiting times, health provider courtesy, clear communication and competent care (clinical examination), as well as prevention of surgical 
complications and improvement of hospital cleanliness. The findings of this study support existing research on the importance of clinical care and positive patient experience for satisfaction; they are the first to show this association in Mexico for hospital care.

\section{Supplementary information}

Supplementary information accompanies this paper at https://doi.org/10. 1186/s12913-019-4706-9.

Additional file 1: Table S1. User experience related to satisfaction with outpatient consultation ( $n=6713$ patients nested within 136 hospitals; year 2017). Table S2. User experience related to satisfaction with outpatient consultation ( $n=10,328$ patients nested within 130 hospitals; year 2016). Table S3. User experience related to satisfaction with surgical care $(n=1082$ patients nested within 124 hospitals; year 2016).

\section{Abbreviations}

Cl: confidence intervals; ENSAT: National Satisfaction Survey; ICD10: International Classification of Diseases 10th revision; IMSS: Mexican Institute of Social Security; PR: prevalence ratios

\section{Acknowledgements}

The authors would like to thank Jesus Flores Catarino, coordinator of the strategic research at IMSS, for the information provided on the ENSAT sampling strategy and response rate.

\section{Authors' contributions}

SVD conceptualized the manuscript, performed the literature review, carried out the data analysis, described methods and study results and wrote the first draft of the manuscript. CIC, SRDW and RPC participated in the conceptualization of this manuscript, critically reviewed the manuscript for significant intellectual content. All authors read and approved the final version of the manuscript, have participated sufficiently in the work to take public responsibility for appropriate portions of the content and agreed to be accountable for all aspects of the work in ensuring that questions related to the accuracy or integrity of any part of the work are appropriately investigated and resolved.

\section{Funding}

The author(s) received no specific funding for this work. The publication of this article was supported by Bill \& Melinda Gates Foundation.

\section{Availability of data and materials}

The data supporting the results reported in this article is available at the IMSS webpage at: http://www.imss.gob.mx/encuesta-nacional/sistemaintegral-de-medicion-de-la-satisfaccion-de-usuarios

\section{Ethics approval and consent to participate}

This study is a secondary data analysis of the ENSAT 2017. The data for the analysis were obtained from the survey public repository hosted at the IMSS webpage at: http://www.imss.gob.mx/encuesta-nacional/sistema-integral-demedicion-de-la-satisfaccion-de-usuarios. This repository has the data already de-identified; thus, it is not possible to trace any of the data to the actual individual. In accordance to the Internal Regulation of the Research Ethics Committee of the National Institute of Public Health in Mexico, this secondary analysis was considered exempt of approval.

\section{Consent for publication}

Not applicable. The article does not contain any individual person's data.

\section{Competing interests}

One of the authors 'Svetlana Vladislavovna Doubova' is an Associate Editor of BMC Health Services Research.

\section{Author details}

${ }^{1}$ Epidemiology and Health Services Research Unit CMN Siglo XXI, Mexican Institute of Social Security, Av. Cuauhtemoc 330, Zip Code: 06720 Mexico
City, Mexico. ${ }^{2}$ Institute of Social Research, National Autonomous University of Mexico, Mexico City, Mexico. ${ }^{3}$ Ifakara Health Institute, Dar es Salaam, Tanzania. ${ }^{4}$ Department of Global Health and Population, Harvard T.H. Chan School of Public Health, 665 Huntington Avenue, Boston, MA 02115, USA.

${ }^{5}$ Center for Health Systems Research, National Institute of Public Health, Universidad No. 655 Colonia Santa María Ahuacatitlán, Zip Code: 62100 CuernavacaCity, Mexico. ${ }^{6}$ Division of Social Protection and Health, Jamaica Country Office, InterAmerican Development Bank, 6 Montrose road, Kingston, Jamaica.

Received: 12 February 2019 Accepted: 31 October 2019

Published online: 21 November 2019

\section{References}

1. Draper M, Cohen $\mathrm{P}$, Buchan $\mathrm{H}$. Seeking consumer views: what use are results of hospital patient satisfaction surveys? Int J Qual Health Care. 2001; 13(6):463-8

2. Naidu A. Factors affecting patient satisfaction and healthcare quality. Int J Health Care Qual Assur. 2009;22(4):366-81.

3. Fenton JJ, Jerant AF, Bertakis KD, Franks P. The cost of satisfaction: a national study of patient satisfaction, health careutilization, expenditures, and mortality. Arch Intern Med. 2012;172(5):405-11.

4. Schneider EC, Zaslavsky AM, Landon BE, Lied TR, Sheingold S, Cleary PD. National quality monitoring of Medicare health plans: the relationship between enrollees' reports and the quality of clinical care. Med Care. 2001; 39(12):1313-25.

5. Sequist TD, Schneider EC, Anastario M, et al. Quality monitoring of physicians: linking patients' experiences of care to clinical quality and outcomes. J Gen Intern Med. 2008:23(11):1784-90.

6. Batbaatar E, Dorjdagva J, Luvsannyam A, Savino MM, Amenta P. Determinants of patient satisfaction: a systematic review. Perspect Public Health. 2017;137(2):89-101.

7. Ware JE, Snyder MK, Wright WR, Davies AR. Defining and measuring patient satisfaction with medical care. Eval Progr Plan. 1983;6:247-63.

8. Dunsch F, Evans DK, Macis M, Wang Q. Bias in patient satisfaction surveys: a threat to measuring healthcare quality. BMJ Glob Health. 2018;3(2):e000694. https://doi.org/10.1136/bmjgh-2017-000694.

9. Hall JA, Dornan MC. Patient sociodemographic characteristics as predictors of satisfaction with medical care: a meta-analysis. Soc Sci Med. 1990:30(7): 811-8.

10. Quintana JM, González N, Bilbao A, Aizpuru F, Escobar A, Esteban C, SanSebastián JA, de-la-Sierra E, Thompson A. Predictors of patient satisfaction with hospital health care. BMC Health Serv Res. 2006;6:102. https://doi.org/ 10.1186/1472-6963-6-102.

11. Nguyen Thi $\mathrm{PL}$, Briançon S, Empereur F, Guillemin F. Factors determining inpatient satisfaction with care. Soc Sci Med. 2002:54(4):493-504.

12. Shou-Hisa C, Ming-Chin Y, Tung-uang C. Patient satisfaction with and recommendation of a hospital: effects of interpersonal and technical aspects of hospital care. Int J Qual Health Care. 2003;15(4):345-55

13. Dierssen-Sotos T, Rodríguez-Cundín P, Robles-García M, Brugos-Llamazares $V$. Factors associated with patient satisfaction with hospital care. An Sist Sanit Navar. 2009:32(3):317-25

14. Deaton AS, Tortora R. People in sub-Saharan Africa rate their health and health care among the lowest in the world. Health Aff (Millwood). 2015; 34(3):519-27.

15. Valentine N, Darby C, Bonsel GJ. Which aspects of non-clinical quality of care are most important? Results from WHO's general population surveys of "health systems responsiveness" in 41 countries. Soc Sci Med. 2008;66(9): 1939-50.

16. Jha AK, Orav EJ, Zheng J, Epstein AM. Patients' perception of hospital care in the United States. N Engl J Med. 2008;359(18):1921-31.

17. Sihuin-Tapia EY, Gómez-Quispe OE, Ibáñez-Quispe V. Satisfaction of hospitalized patients in a hospital in Apurimac, Peru. Rev Peru Med Exp Salud Publica. 2015;32(2): :299-302.

18. Cabello E, Chirinos JL. Validation and applicability of SERVQUAL modified survey to measure external user satisfaction in health services. Rev Med Hered. 2012:23(2):88-95.

19. Seclén-Palacin J, Darras C. Satisfaction of users of health services: associated sociodemographic and accessibility factors. Perú, 2000. An Fac Med Lima. 2005;66(2):127-41. 
20. Olaiz-Fernández G, Rivera-Dommarco J, Shamah-Levy T, Rojas R, VillalpandoHernández S, Hernández-Avila M, et al. Encuesta Nacional de Salud y Nutrición 2006. [National Health and Nutrition Survey 2006] Cuernavaca, Mexico: Instituto Nacional de Salud Pública; 2006.

21. Gutiérrez JP, Rivera-Dommarco J, Shamah-Levy T, Villalpando-Hernández S, Franco A, Cuevas-Nasu L, et al. Encuesta Nacional de Salud y Nutrición 2012. Resultados nacionales. [National Health and nutrition survey 2012. National results.] 2a. Ed. Instituto Nacional de Salud Pública: Cuernavaca, Mexico; 2013.

22. Ortiz-Espinosa RM, Muñoz-Juárez S, Torres-Carreño E. User satisfaction among fifteen hospitals in Hidalgo. Mexico Rev Esp Salud Pública. 2004; 78(4):527-37.

23. Instituto Mexicano del Seguro Social. Report to the Federal Executive and the Congress of the Union on the financial situation and risks of the Mexican Social Security Institute 2016-2017. Primera Edición México; 2017.

24. Kruk ME, Gage AD, Arsenault C, Jordan K, Leslie HH, Roder-DeWan S, et al. High-quality health systems in the sustainable development goals era: time for a revolution. Lancet Glob Health. 2018;6(11):e1196-252. https://doi.org/ 10.1016/S2214-109X(18)30386-3.

25. Instituto Nacional de Estadística Geografía e Informática. Regiones Socioeconómicas de México. Antecedentes y metodología. [National Institute of Statistics, Geography and Information Technology. Socioeconomic Regions of Mexico. Background and methodology.] Mexico; 2000. Available from: http://www.inegi.org.mx/est/contenidos/espanol/ sistemas/regsoc/default.asp?s=est\&c=11723

26. Barros AJ, Hirakata VN. Alternatives for logistic regression in cross-sectional studies: an empirical comparison of models that directly estimate the prevalence ratio. BMC Med Res Methodol. 2003; 3: 21. Available from: https://doi.org/10.1186/1471-2288-3-21.

27. Seaman $S R$, White IR. Review of inverse probability weighting for dealing with missing data. Stat Methods Med Res. 2013;22:278-95.

28. Doyle $C$, Lennox L, Bell D. A systematic review of evidence on the links between patient experience and clinical safety and effectiveness. BMJ Open. 2013;3(1). pii: e001570. doi: https://doi.org/10.1136/bmjopen-2012-001570

29. Brach C, Keller D, Hernandez LM, Baur, C, Parker, R, Dreyer, B, et al. Ten Attributes of Health Literate Health Care Organizations. Discussion Paper. Institute of Medicine, Washington DC; 2012.

30. Bao Y, Fan G, Zou D, Wang T, Xue D. Patient experience with outpatient encounters at public hospitals in Shanghai: Examining different aspects of physician services and implications of overcrowding. PLoS One. 2017 16; 12(2):e0171684. doi: https://doi.org/10.1371/journal.pone.0171684

31. Khan NA, Aslam SK, Rehman AU, Qureshi MS, Inam S, Samo KA, et al. Satisfaction level and its predictors among out patients at public sector hospital in Karachi. J Dow Uni Health Sci. 2014;8(3):104-10.

32. Cheng SH, Yang MC, Chiang TL. Patient satisfaction with and recommendation of a hospital: effects of interpersonal and technical aspects of hospital care. Int J Qual Health Care. 2003;15(4):345-55.

33. Zolnierek KB, Dimatteo MR. Physician communication and patient adherence to treatment: a meta-analysis. Med Care. 2009;47(8):826-34.

34. Stewart MA. Effective physician-patient communication and health outcomes: a review. CMAJ. 1995;152(9):1423-33.

35. Ekpe EE, Peter Al. Surgical patient's satisfaction with services at a tertiary hospital in south -south state of Nigeria. J Med Res. 2016;2(5):157-62.

36. Viberg N, Forsberg BC, Borowitz M, Molin R. International comparisons of waiting times in health care--limitations and prospects. Health Policy. 2013;112(1-2):53-61.

37. McKinnon K, Crofts PD, Rhiannon E, et al. The outpatient experience: results of a patient feedback survey. Int J Health Care Qual Assur Inc Leadersh Health Serv. 2006;11(5):156-60.

38. Infante-Castañeda C. Quejas médicas. [Medical complaints. Patient dissatisfaction with the quality of medical care.] México: Ed. Textos Mexicanos; 2006. ISBN 968-5610-47-9.

39. Ivarsson B, Larsson S, Sjoberg T. Postponed or cancelled heart operations from the patient's perspective. J Nurs Manag. 2004;12:28-36.

40. Tait AR, Voepel-Lewis T, Munro HM, et al. Cancellation of pediatric outpatient surgery: economic and emotional implications for patients and their families. J Clin Anesth. 1997;9:213-9.

41. Siti Munira Yasin, Nazri Syamil Abdull Latip. Hilwati Hashim4 and Mazlifah Omar. Determinants of Patient's Satisfaction towards Hospital Services in a Specialist Centre. Pertanika J Sci \& Technol.2017; 25 (S): 169-78.

42. Schoenfelder T, Klewer J, Kugler J. Determinants of patient satisfaction: a study among 39 hospitals un an in-patient setting in Germany. Int J Qual Health Care. 2011;23(5):503-9.
43. Infante C, Ruíz A. [medical complaints for surgical complications.] Memorias del 1er Congreso Académico. Mexico, D.F.: Facultad de Medicina. UNAM; 2005

44. Gurland BH, Merlino J, Sobol T, Ferreira P, Hull T, Zutshi M, et al. Surgical complications impact patient perception of hospital care. J Am Coll Surg. 2013;217(5):843-9.

45. Sheetz KH, Waits SA, Girotti ME, Campbell DA Jr, Englesbe MJ. Patients' perspectives of care and surgical outcomes in Michigan: an analysis using the CAHPS hospital survey. Ann Surg. 2014;260(1):5-9.

46. Zhang Y, Rohrer J, Borders T, Farrell T. Patient satisfaction, self-rated health status, and health confidence: an assessment of the utility of single-item questions. Am J Med Qual. 2007;22(1):42-9.

47. Willis R, Evandrou M, Pathak P, Khambhaita P. Problems with measuring satisfaction with social care. Health Soc Care Community. 2016;24:587-95.

48. Carr-Hill R. The measurement of patient satisfaction. J Public Health Med. 1992;14:236-49.

49. Locker D, Dunt D. Theoretical and methodological issues in sociological studies of consumer satisfaction with medical care. Soc Sci Med. 1978;12: 283-92.

50. Ofili OU. Patient satisfaction in healthcare delivery- a review of current approaches and methods. Eur Sci J. 2014;10:25-39.

51. Crow R, Gage H, Hampson S, Hart J, Kimber A, Storey L, Thomas H. The measurement of satisfaction with healthcare: implications for practice from a systematic review of the literature. Health Technol Assess. 2002;6:1-244.

\section{Publisher's Note}

Springer Nature remains neutral with regard to jurisdictional claims in published maps and institutional affiliations.
Ready to submit your research? Choose BMC and benefit from:

- fast, convenient online submission

- thorough peer review by experienced researchers in your field

- rapid publication on acceptance

- support for research data, including large and complex data types

- gold Open Access which fosters wider collaboration and increased citations

- maximum visibility for your research: over $100 \mathrm{M}$ website views per year

At $\mathrm{BMC}$, research is always in progress.

Learn more biomedcentral.com/submissions 